\title{
INNOVATION OF THE USE OF HONEY AS A TOPICAL MEDICINE TO THE THERAPY OF ABDOMEN'S INCISION POST-CESAR
}

\author{
Muhammad Rizki Darmawan, Nur Mahampang, Dwi Lisa Nur'aini \\ Faculty of Medicine. Universitas Sriwijaya, Palembang. Indonesia \\ lisa_m267@yahoo.co.id
}

\begin{abstract}
Honey has long been used as food and medicine. One of the many researched benefits of honey is that it speeds up wound healing. The Koran and the hadiths clearly state that there is healing in honey. Along with advances in technology, cesarean delivery is increasingly being performed to help facilitate labor under various indications. However, cesarean delivery can limit the mother's activities in the care of herself and her child.

On the other hand, cesarean delivery also often causes obstetric complications such as puerperal infection, endometritis, wound complications, and surgical healing complications. It will increase the cost of cesarean delivery. The authors reviewed the data regarding the effectiveness of honey in the therapy of postcesarean delivery abdominal incisions. The data show that the antibacterial, anti-inflammatory, and antioxidant characteristics of honey can significantly affect the therapy of cesarean delivery incisions. The combination of the osmotic effect and hydrogen peroxide activity in honey can inhibit bacterial growth, reduce edema, exudate, and pain due to inflammatory processes. Besides, honey has the effect of protecting antioxidant enzymes from free radicals and reducing oxidative stress to reduce cell damage. Honey can also stimulate angiogenesis, the proliferation of fibroblasts and epithelial cells, and granulation, helping speed up the healing process. This paper discusses honey's mechanism in accelerating wound healing and its effect in preventing wound infection from improving the quality of health and the relationship between mother and child after cesarean delivery.
\end{abstract}

Keywords: honey, topical medicine, cesarean delivery, incision, infection 


\section{INTRODUCTION}

Along with technological developments, the cesarean delivery rate is now increasing in both developed and developing countries, especially in big cities. Cesarean delivery is increasingly being performed for various medical indications, including pelvic floor injuries due to vaginal delivery and preterm birth, aiming to reduce the risk of fetal injury. Meanwhile, studies show that elective cesarean delivery almost triples the risk of maternal death (Cunningham et al. 2012, pp. 568-572). According to the World Health Organization (WHO), in 2010, 54 countries had a cesarean delivery rate below 10\%, while 69 other countries had over 15\%. Basic Health Research Data (RISKESDAS) in 2010 showed that the rate of cesarean delivery in Indonesia was $15.3 \%$, with the lowest rate in Southeast Sulawesi at 5.5\% and the highest rate in DKI Jakarta at 27.2\% (Andayasari et al. 2015). Although it can help facilitate labor in specific indications, cesarean delivery affects maternal mortality and morbidity. There is an almost 25-fold increase in mortality from infection in cesarean section compared to vaginal deliveries. Meanwhile, the maternal morbidity rate doubled in cesarean delivery. (Cunningham et al. 2012, pp. 568572).

Many risks can arise due to cesarean delivery, ranging from short-term to longterm risks to both mother and child. Short-term risks to cesarean delivery include an increased risk for infection and a lower propensity for breastfeeding. Wound infection and/or hematoma accounts for 3\% of cesarean deliveries (Gregory et al. 2011). Cunningham et al. (2012, pp. 568-572) mentions the number of obstetric complications such as puerperal infection, endometritis, wound complications, and surgical healing complications. This will increase the cost of cesarean delivery. The Koran mentions the existence of healing in honey for humans. Rasulullah has also mentioned drinking honey as one of the three things in which there is healing. It shows the specialty of honey as a medicine. Natural honey contains about 200 substances, including amino acids, vitamins, minerals, and enzymes, with sugar and water as the main ingredients (Eteraf-Oskouei and Najafi 2012).

One of the many researched benefits of honey is its wound healing properties. Studies report that honey plays a role in the wound healing process because it has antibacterial, anti-inflammatory, and antioxidant characteristics. These characteristics are caused by several things found in honey, including hydrogen peroxide, flavonoids, vitamin $\mathrm{C}$, low $\mathrm{pH}$, hygroscopic properties, and osmotic effects. Research has shown that honey is an effective broad-spectrum antibacterial agent (Al-Waili 2011; Eteraf-Oskouei 2012; Yaghoobi 2013). Based on the above matters, this paper examines honey's effectiveness as a topical medicine in accelerating wound healing and preventing infection of the abdominal incision so that it is hoped that it can improve the welfare of mothers and children after cesarean delivery. In collecting data on this paper, the writing team used the literature study technique that was carried out by collecting data related to the problems discussed in this paper. The data used to support library references are obtained from several existing library sources, including textbooks, previous research, and scientific journals. Previous research data is used to analyze the strengths and 
weaknesses of existing research. Then the writing team processed the existing data to find problems that could be analyzed. Furthermore, information related to problems obtained from previous theories is combined with data from studies that have been conducted by previous researchers to obtain new solutions or ideas by developing innovative use of honey related to post-cesarean section problems.

\section{Discussion}

Recent advances in medical science have helped health workers take medical measures to reduce the risk and failure rate of medical treatment, one of which is a medical treatment in birth. Previously, the birth technique used in the community was only the usual vaginal birth technique. Normal vaginal birth ( vaginal delivery) is the normal birth process that usually does not require action or medical intervention significantly. However, certain conditions occur in mothers and babies that increase the risk of failed delivery through the normal route and lead to both mother and baby's death. The World Health Organization in 2005 wrote that the average maternal mortality due to vaginal births per year ranges from 1,000 to 1,500 out of 100,000 births. For this reason, birth techniques have been developed along with the increasing modernity and development of medical science, one of which is the technique of cesarean delivery.

The cesarean delivery technique is performed by incising the abdominal wall and uterus. This action is performed in certain circumstances and has medical indications that must be taken into account. In certain circumstances, this action is recommended but in other conditions it is not necessary. Therefore, WHO as the parent of world health in Gibbons et al. (2010) recommends limiting caesarean section only at certain levels and necessary medical conditions. This is because a cesarean section, like any other operation, can pose certain risks and affect the quality of a mother's care after a cesarean section. The cesarean section's risks related to the mother-child relationship's quality include the longer time to heal than a normal vaginal delivery. Research shows 1 in 10 mothers who give birth by cesarean section experience difficulty with normal activities at two months postpartum (reports The Coalition for Improving Maternity Service ). The postoperative recovery time is longer than that of vaginal delivery, will reduce the effective time for mothers to care for children and reduce contact between mother and child because mothers still need post-cesarean care.

Another problem that arises is the limitation of maternal activity during postcesarean section recovery, including body position adjustment so that the stitches are not removed at the incision site. This results in limited child care activities by mothers, including breastfeeding. If the breastfeeding process is carried out, there are still time restrictions and position adjustments so that the care measures do not result in the wound's opening in the incision area. Another problem is the tendency to return to the hospital (rehospitalization) after the mother is hospitalized and pain in part or all of the incision area. Pain in the incision area increases the likelihood of requiring hospitalization and the duration of the recovery process. According to The Coalition for Improving Maternity Service, 1 in 4 mothers who deliver by cesarean section experience pain in the incision area as the main complaint, and 1 in 14 women still report complaints 
of pain in the incision area 6 months or more after surgery. Also, the pain in the incision area reduces the feeling of comfort for the mother in caring for the child, including in the breastfeeding process. There is a tendency for patients to have difficulty with cesarean section in breastfeeding children. Furthermore, the cesarean section also has a risk of infection after cesarean section. The infection after cesarean section will undoubtedly prolong the healing period and require additional therapy to cure the infection, even significantly increasing the likelihood of rehospitalization. All of the risks affect the relationship between mother and child, starting from contact with the effectiveness of parenting time and leading to the mother and child's well-being.

From the explanation above, the main problems in the form of a length of healing time, activity restrictions, the presence of pain in the healing process, rehospitalization, and the possibility of infection during the healing process affect the relationship between mother and baby and the baby's parenting style for a certain period after birth. So in this paper, the author examines the innovation of using honey as a topical medicine for postcesarean section wound therapy. Many researchers have reported that honey can heal wounds and prevent infection. In general, wound healing is influenced by two things: endogenous factors (the healing process of components in the body) and exogenous factors or microorganism factors. Postoperative healing time is closely related to endogenous factors but influenced by exogenous factors as agents of infection. Examples of microorganisms that are the most common etiology of wound infections are Staphylococcus aureus and the pathogen Pseudomonas aeruginosa, which often infects chronic wounds. Honey has ingredients that can speed up the wound healing process after cesarean section and prevent infection because it has antibacterial properties.

In Islam, the use of honey as a medical medium is found in the Koran and hadiths. The use of honey as a medicinal medium is stated in the Qur'anic chapter 16 (AnNahl) verses 68-69, which reads, "And your Rabb inspires the bees: 'make nests on the hill, on wooden trees, and in places for humans. Then eat from each one and walk the path of your Lord, made easy (for you). From the bee's stomach comes a drink (honey) of various colors, in which there is healing medicine for humans. In fact, there really is a sign (Greatness of Rabb) for those who think (QS.16 An-Nahl: 68-69). " Apart from that, the Messenger of Allah said, "You should use two medicines, namely honey and the Koran" (Hadith No. 3452, Chapter Honey in the Sunan Ibn Majah Book). This was proven by researchers about honey and the world of medicine, especially in the treatment of wounds. The content of honey and conditions that play a role in healing cesarean section wounds include:

Hydrogen Peroxide as an Antiseptic and Stimulating Agent for wound healing . Glucose oxidase, one of the enzymes of carbohydrate metabolism, is added by bees to honey extract (nectar) and converts glucose into hydrogen peroxidase and gluconic acid under aerobic conditions. According to some literature, hydrogen peroxidase production by glucose oxidase in honey is very high and increases unequally at different dilution levels. Effect of $\mathrm{H}_{2} \mathrm{O}_{2}$ in honey in trials in vitro and in vivo stimulated proliferation of fibroblasts in the wound area. The role of fibroblasts is to actively synthesize the matrix in the wound healing process, including collagen and scar tissue that will cover the cesarean incision wound. The effect of $\mathrm{H}_{2} \mathrm{O}_{2}$ stimulus on fibroblast proliferation accelerates the incision wound's healing process. 
Non peroxide and Antioxidant Activity. The antibacterial activity of honey is maintained in the presence of a catalase reaction to eliminate $\mathrm{H}_{2} \mathrm{O}_{2}$ activity. Honey with the Manuka type, which is known to come from New Zealand has nonperoxide antibacterial activity. The antioxidant effect is explained by looking at the relationship of oxygen radicals to the inflammatory process. Oxygen radicals cause inflammation and tissue damage. In this condition, the role of honey is to inactivate free iron, which will catalyze free radical oxidation produced by hydrogen peroxidase. Dark honey types have a better antioxidant function than light honey because they are not eliminated due to catalase activity and nonperoxidase components.

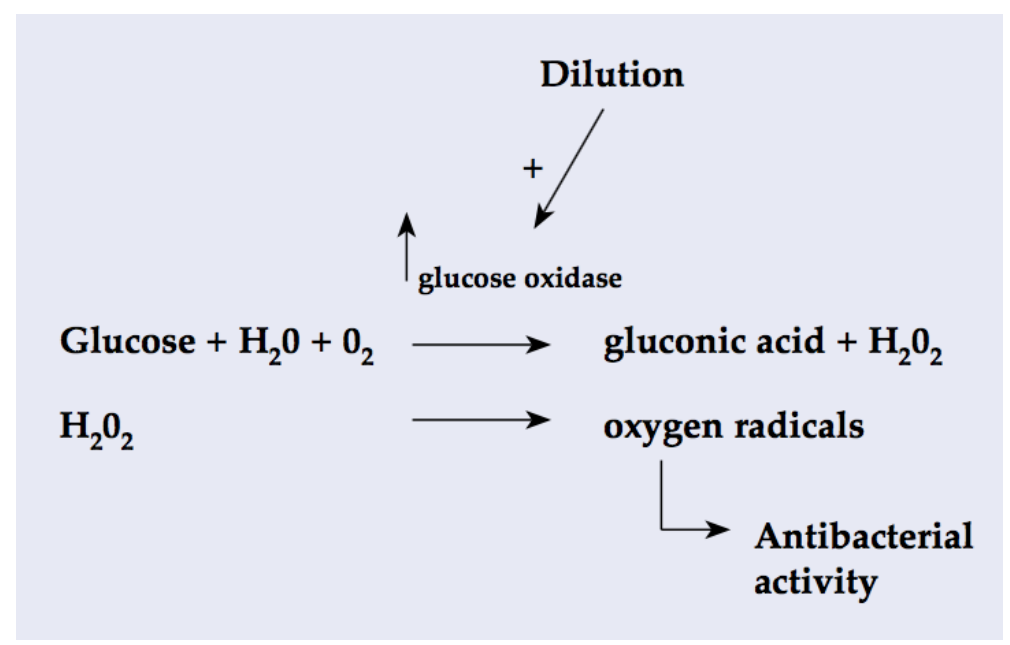

Figure 1. Chemical Debridement Action ( Source: Mwipatayi, et al. 2004. The Use of Honey in Chronic Leg Ulcers)

\section{Honey Osmolarity}

In liquids or solutions with high osmolarities, such as honey, glucose, and sugar paste, they can inhibit microbial growth because the sugar molecules bind to water molecules so that bacteria do not have enough water to develop prevention of infection can occur and accelerated healing is obtained. This effect can occur with the use of honey topically on wounds, including post-surgical wounds or incisions.

\section{Increased activity lymphocytic and phagocytic}

In a study of 3 types of honey (Manuka, Pasture, and Jelly Bush) in the United Kingdom on the effect of releasing inflammatory cytokines mediators from MM6 cells, namely monocytic cells in humans with the characteristics of mature monocyte cells. The results of the study indicated that all types of honey used as the research material significantly increased the release of TNF- $\alpha$, IL-1 $\beta$, and IL- 6 from MM6 cells. This study found that the effect of honey on wound treatment was related to the stimulation of cytokine release from monocyte cells, which has a role in tissue repair and healing. In cell culture, the results showed that honey can stimulate B and T lymphocytes' proliferation and activation.

\section{Acidity or Acidity}

In chronic wounds that have not healed or not healed will produce an alkaline environment. Lowering wound $\mathrm{pH}$ can decrease protease activity, increase fibroblast activity, increase oxygen release, and continuously treat wounds. The sugar and acid 
content in honey can trigger the activity of eliminating bacteria by macrophages. An Irish study showed an association between a decrease in $\mathrm{pH}$ and a decrease in wound size. Therefore, the topical acidity produced by honey can help accelerate post-cesarean wound healing.

\section{Nitric Oxide}

Nitric Oxide (NO) is essential for healing, killing bacteria, preventing viral infections, and related to immunological responses. The role of NO related to wound healing is in the inflammatory and proliferative stages. The wound healing process involves platelets, inflammatory cells, fibroblasts, and epithelial cells, all of which can produce NO. Honey contains NO end products, and honey can increase NO products' production in body fluids such as urine, saliva, and plasma. This explains how honey can affect the acceleration of wound healing and associated wound infection after cesarean section.

\section{Plasma Prostaglandin Decreasing Effects}

As is well-known, prostaglandins are mediators of inflammation and pain. Prostaglandins can reduce the function of $\mathrm{T}$ and $\mathrm{B}$ lymphocytes by inhibiting the production of antibodies by B lymphocytes and increasing the induction of T lymphocyte suppressors to reduce immunity. Honey can reduce the concentration of prostaglandins in plasma in normal individuals. The mechanism of action can be COX-1 or COX-2 or both. Natural honey has the effect of decreasing prostaglandins in plasma, which can provide therapeutic effects related to reducing pain, increasing immunity, and accelerating the wound healing process.

\section{Increased Antibody Production}

The effect of increasing the production of antibodies will be related to the NO content and increase the production of NO products by honey because NO is very important for the immune response. Apart from that, honey's function can reduce the concentration of prostaglandins in the plasma, resulting in a decrease in the inhibitory activity of antibody production so that the healing process can be carried out more quickly.

\section{Conclusion}

Cesarean section has a risk of action and a risk of complications after surgery. In this paper, the authors focus on the impact of the post-cesarean section on mother and child and the quality of postnatal mother-child relationships. The long healing process, activity restrictions, the risk of rehospitalization after the first postoperative treatment, the main complaints of cesarean section incision pain, and the risk of infection in the cesarean section incision wound are the causes of the lack of quality of the relationship between mother and child after birth. Honey as a thibbun nabawi has been used by the Prophet and is described in the Islamic religious arguments in the form of the Koran and hadith. It has been strengthened by research evidence about its effect on accelerating the process of wound healing after cesarean section. Honey plays a role in preventing wound infection due to incisions during surgical operations and improving the quality of health 
and postnatal relations between mother and child so that the welfare of mother and child can increase.

\section{References}

Akanni, SM 2013, 'An Exposition of Islamic Medication in The Light of The Quran and Hadith' , 1st Annual International Interdisciplinary Conference, Azores, accessed on 5 August 2016, http://eujournal.org/index.php/esj/article / downloads / 1326/1335

Al-Waili, NS, Khelod, S, Ahmad, AA 2011, Honey for Wound Healing, Ulcers, and Burns: Data Suporting Its Use in Clinical Practice, TheScientificWorldJOURNAL , p. 766787, Riyadh.

Andayasari, L et al. 2015, Proportion of Sesarea Sections and Factors Associated with Sesarea Sections in Jakarta , Health Research Bulletin, vol. 43, no. 2, h. 105-116, Jakarta.

Barret, J. 2014, 'Recovering on Cesarean: Tips on Healing', accessed 4 August 2016, http://www.ican-online.org/wp-content/uploads/2014/06/Recovering-From-ACesarean-Tips-On-Healing.pdf

Becher, L \& Siril, S 2013, 'Indications for Cesarean Section in St. Joseph Medical Hospital Moshi, Tanzania', Student Thesis, University of Oslo, accessed on 4 August 2016, https://www.duo.uio.no/ bitstream / handle / 10852/35663 / Prosjektoppgave_medisin.pdf? sequence $=2$

Buhimsci, CS \& Carl, PW 2009, Medication on Pregnancy and Lactation. , American College of Obstetricians and Gynecologists Journal, vol. 113, no. 2, part 1, New Haven

Children Connection. 2006, 'Vaginal Birth and Cesarean Birth: How Do The Risk Compare', accessed on 5 August http://www.pqcnc.org/documents/sivbdoc/sivbeb/8ChildbirthConnectionVaginalBirt handCesareanBirthRiskComparison.pdf

Claire, J. 2009, 'C Section Guide', accessed August 4, 2016, http://bestcsectionrecovery.com/wp-content/download/C-Section_Guide_Booklet.pdf

Cunningham, F. Gary et al. 2012, Williams Obstetrics, Issue 23, Vol. 1, EGC, Jakarta.

Department of Health 2015, 'Government of Western Australia: Your Caesarean Birth and Recovery', accessed 5 August 2016, http://www.kemh.health.wa.gov.au/brochures/consumers/wnhs0011.pdf

Dorland, WAN 2014, Dorland Medical Pocket Dictionary Edition 28 , EGC, Jakarta.

Eteraf-Oskouei, T \& Najafi, M 2012, Traditional and Modern Uses of Natural Honey in Human Diseases: A Review , Iranian Journal of Basic Medical Sciences, Tabriz. 
Gibbons, L, Belizán, JM, Lauer, JA, Betrán, AP, Merialdi, M, \& Althabe1, F 2010, The Global Numbers and Costs of Additionally Needed and Unnecessary Caesarean Sections Performed per Year: Overuse as a Barrier to Universal Coverage, Geneva, accessed August 22, 2016, http://www.who.int/healthsystems/topics/financing/healthreport/30Csectioncosts.pdf

Gur, R, Duggal, SD, Rongpharpi, SR, Srivastava, R, Kumar, A, Gupta, V, Chawla, D, Pundhir, S 2015, Post Caesarean Surgical Site Infection , iMedPub Journals, Vol. 6, No. 1: 4, Delhi.

Haynes, JS \& Callaghan, R 2011, Properties of honey: its mode of action and clinical outcomes, Wounds UK, vol. 7, no. 1

Jones, W 2014, 'Antibiotics and Breastfeeding', The Breastfeeding Network, accessed 5 August 2016, https://www.breastfeedingnetwork.org.uk/wpcontent/dibm/antibiotics- oct-14.pdf

Kealy, MA, Small, RE, \& Liamputtong, P 2010, 'Recovery after caesarean birth: a qualitative study of women's accounts in Victoria, Australia, accessed August 4, 2016, http://bmcpregnancychildbirth.biomedcentral.com/articles/10.1186 / 14712393-10-47

Kuguoglu, S, Yildiz, H, Tanir, MK, Demirbag, BC 2012, Breastfeeding After a Cesarean Delivery, InTech, Rijeka.

Mwipatayi, BP, Angel, D, Norrish, J, Hamilton, MD, Scott, A., Sieunarine, K 2004, 'The Use of Honey in Chronic Leg Ulcers ', Department of Vascular Surgery Royal Perth $\begin{array}{lllll}\text { Hospital, } & \text { accessed } & 4 & \text { August }\end{array}$ , http://www.awma.com.au/journal/1203_01.pdf

The American College of Obstetricians and Gynecologists 2015, 'Cesarean Birth (CSection)', accessed 5 August 2016, http://www.acog.org/Patients/FAQs/CesareanBirth-C-Section

The Coalition for Improving Maternity Services. 2015, 'The Risks of Cesarean Delivery to Mother and Baby', accessed 5 August 2016, http://www.motherfriendly.org/Resources/Documents/TheRisksofCesarea nSec tionFebruary2010.pdf

World Health Organization 2015, WHO Statement on Caesarean Section Rates, WHO, Geneva.

Yaghoobi, R, Kazerouni, A, \& Kazerouni, 0 2013, Evidence for Clinical Use of Honey in Wound Healing as an Antibacterial, Anti-inflammatory Anti-oxidant and Anti-viral Agent: A Review, Jundishapur Journal of Natural Pharmaceutical Products , Ahvaz. 